\title{
CD4 Tcells are required for both development and maintenance of disease in a new mouse model of reversible colitis
}

\author{
J Brasseit $^{1,6}$, E Althaus-Steiner ${ }^{1,6}$, M Faderl $^{1}$, N Dickgreber ${ }^{1}$, L Saurer $^{1}, \mathrm{~V}$ Genitsch $^{2}$, T Dolowschiak ${ }^{3}$, \\ $\mathrm{H} \mathrm{Li}^{4}, \mathrm{D}$ Finke ${ }^{5}, \mathrm{~W}-\mathrm{D} \mathrm{Hardt}^{3}, \mathrm{KD} \mathrm{McCoy}{ }^{4}, \mathrm{AJ}$ Macpherson ${ }^{4}, \mathrm{~N} \mathrm{Corazza}^{1}, \mathrm{M}$ Noti $^{1}$ and C Mueller $^{1}$
}

Current therapies to treat inflammatory bowel diseases have limited efficacy, significant side effects, and often wane over time. Little is known about the cellular and molecular mechanisms operative in the process of mucosal healing from colitis. To study such events, we developed a new model of reversible colitis in which adoptive transfer of $\mathrm{CD} 4{ }^{+}$CD45RB ${ }^{\text {hi }}$ T cells into Helicobacter typhlonius-colonized lymphopenic mice resulted in a rapid onset of colonic inflammation that was reversible through depletion of colitogenic Tcells. Remission was associated with an improved clinical and histopathological score, reduced immune cell infiltration to the intestinal mucosa, altered intestinal gene expression profiles, regeneration of the colonic mucus layer, and the restoration of epithelial barrier integrity. Notably, colitogenic T cells were not only critical for induction of colitis but also for maintenance of disease. Depletion of colitogenic Tcells resulted in a rapid drop in tumor necrosis factor $\alpha$ (TNF $\alpha$ ) levels associated with reduced infiltration of inflammatory immune cells to sites of inflammation. Although neutralization of TNF $\alpha$ prevented the onset of colitis, anti-TNF $\alpha$ treatment of mice with established disease failed to resolve colonic inflammation. Collectively, this new model of reversible colitis provides an important research tool to study the dynamics of mucosal healing in chronic intestinal remitting-relapsing disorders.

\section{INTRODUCTION}

Animal models of colitis have significantly contributed to the understanding of the pathogenesis of inflammatory bowel diseases (IBD) and resulted in the identification of a wide range of clinically approved immunological targets and therapeutic objectives for the treatment of IBD. ${ }^{1}$ Although existing therapeutic approaches efficiently attenuate inflammatory processes during active disease, little is known about the pathways operative in maintaining remission in colitis and associated mucosal healing. ${ }^{2}$ Repeated damage to the intestinal epithelium and associated alterations in intestinal epithelial barrier integrity are key features of IBD. ${ }^{3}$ A leaky intestinal epithelial barrier favors translocation of commensal bacteria to the underlying mucosa causing uncontrolled activation of immune cells resulting in chronic intestinal inflammation and associated tissue damage. ${ }^{4,5}$ Suppression of inflammation and restoration of intestinal barrier integrity to limit uncontrolled exposure to luminal microbes and antigens is key for induction of remission in colitic mice and associated mucosal healing. Studies from humans and mice suggest that following inflammation-induced damage and epithelial erosions, intestinal epithelial cells (IECs) rapidly increase their proliferative capacity to restore barrier integrity. ${ }^{6-8}$ This process is partially mediated by growth factors (e.g., epidermal growth factor, fibroblast growth factor), cytokines (e.g. transforming growth factor- $\beta$, interleukin (IL)-6, IL-22), anti-inflammatory signaling pathways (via Trem2), ${ }^{9}$ or microbial-derived products (lipopolysaccharide, $\mathrm{CpG})^{10}$ that directly act on IECs to

\footnotetext{
${ }^{1}$ Division of Experimental Pathology, Institute of Pathology, University of Bern, Bern, Switzerland. ${ }^{2}$ Division of Clinical Pathology, Institute of Pathology, University of Bern, Bern, Switzerland. ${ }^{3}$ Institute of Microbiology, ETH Zürich, Zurich, Switzerland. ${ }^{4}$ Maurice E. Müller Laboratories, University Clinic for Visceral Surgery and Medicine, University of Bern, Bern, Switzerland and ${ }^{5}$ Division of Developmental Immunology, Department of Biomedicine, University of Basel, Basel, Switzerland. Correspondence: C Mueller (christoph.mueller@pathology.unibe.ch)

${ }^{6}$ These authors contributed equally to this work.

Received 3 December 2014; accepted 6 August 2015; published online 16 September 2015. doi:10.1038/mi.2015.93
} 
stimulate intracellular signaling cascades such as nuclear factor- $\mathrm{\kappa B}$ and signal transducer and activator of transcription factor-3 to enhance survival and proliferation of IECs to replenish damaged or dead cells..$^{6,11-13}$ A better understanding of the cellular and molecular processes operative during mucosal healing may help to develop new therapeutic intervention strategies that in concert with existing treatment protocols could help to maintain remission in patients with IBD.

The limited knowledge on how mucosal healing is regulated in chronic intestinal remitting-relapsing disorders can be attributed to the lack of suitable model systems where remission is consistently induced in animals with established disease. Experimental systems that lead to a self-limiting inflammatory response against pathogens in the intestinal mucosa, such as infection with Citrobacter rodentium, a murine-specific bacterial pathogen that is closely related to the human pathogens enteropathogenic Escherichia coli and enterohemorrhagic E. coli $^{14}$ and a mouse model of Salmonella-infection in streptomycin-treated mice ${ }^{15}$ have been instrumental not only in identifying key factors, host-, microbiota-, or pathogenderived, which affect the successful infection, but also clearance of the pathogen. However, in these models of self-resolving bacterial-induced intestinal inflammation, pro-inflammatory, anti-inflammatory, and pro-resolving mechanisms may be simultaneously operative making it difficult to study early cellular and molecular pathways implicated in mucosal healing from acute intestinal inflammation. In addition to infectioninduced models of intestinal inflammation, exposure of mice to dextran sodium sulfate (DSS) in the drinking water to induce acute or chronic intestinal inflammation has been used to study resolution of colitis upon replacement of DSS with normal water. However, the kinetics and the severity of colitis in the DSS colitis model are critically influenced by a number of factors, such as the intestinal microbiota, or differences in the amount of water and DSS consumed by individual mice. This often results in highly variable kinetics of colitis development and, hence, an unpredictable extent of remission induction from colitis. ${ }^{16}$ Further, adoptive transfer of sort-purified regulatory $\mathrm{T}$ cells (Tregs) into colitic $\mathrm{CD}^{+}{ }^{+} \mathrm{CD}_{45} \mathrm{RB}^{\text {hi }}$ transferred into lymphopenic mice has been demonstrated to promote resolution from T-cell-mediated intestinal inflammation in most recipients within 10-14 weeks after transfer. ${ }^{17}$ Although this elegant model proved the potential of Tregs to reverse established colitis in an IL-10-dependent manner, ${ }^{18}$ the considerable variation observed in the proliferative expansion of transferred Tregs and the delay until first indications of remission make it difficult to reliably define key mechanisms operative in resolution induction. Hence, a major disadvantage of these previously described remitting models of colitis is the unpredictable timing and extent of remission induction.

Here we developed a new mouse model of reversible T-cell colitis in which induction of remission in colitic mice can be timed precisely by antibody-mediated depletion of colitogenic $\mathrm{T}$ cells in mice with established disease. Depletion of CD4 T cells in Helicobacter typhlonius-colonized $\left(\mathrm{H}^{+}\right)$lymphopenic hosts previously transferred with $\mathrm{CD} 4{ }^{+} \mathrm{CD}_{4} 5 \mathrm{RB}^{\text {hi }} \mathrm{T}$ cells to induce active intestinal inflammation resulted in rapid mucosal healing within 10-11 days after first antibody treatment characterized by rapid regeneration of the mucus layer and restoration of intestinal epithelial barrier integrity. Importantly, anti-CD4 treatment led to a rapid drop of circulating and colonic tumor necrosis factor $\alpha$ (TNF $\alpha$ ) levels associated with reduced innate immune cell infiltration to sites of inflammation. However, the disease-remitting effect of anti-CD4 treatment could not be solely attributed to the observed rapid decrease in systemic and intestinal TNF $\alpha$ levels, as neutralization of TNF $\alpha$ in mice with active colitis failed to induce remission. Employing this new model system, we characterized cellular and molecular processes associated with treatmentinduced remission in colitis and mucosal healing with the aim to further substantiate the value of this model for both mechanistic and preclinical efficacy studies.

\section{RESULTS}

\section{Depletion of colitogenic CD4 T cells rapidly induces remission in intestinal inflammation}

Mucosal healing is emerging as a new key treatment goal in IBD as induction and maintenance of clinical remission by targeting excessive local immune responses has proven insufficient to change the natural history of IBD. ${ }^{2}$ In order to study mucosal healing in the context of IBD, we established a new animal model to investigate cellular and molecular mechanisms associated with remission in mice with active colitis. To do so, we first induced active intestinal inflammation by adoptive transfer of $\mathrm{CD} 4{ }^{+} \mathrm{CD} 45 \mathrm{RB}^{\text {hi }} \mathrm{T}$ cells into $\mathrm{H}^{+}$lymphopenic mice prior to repetitive administration of CD4-depleting antibodies (Figure 1a). Therapeutic administration of anti-CD4 antibodies to mice with established disease (clinical scores 8-10) resulted in a rapid improvement of clinical signs as early as $24 \mathrm{~h}$ after CD4 T-cell depletion, characterized by reduced weight loss and occurrence of diarrhea that resolved within 11 days after first antibody treatment (Figure 1b). Although mice with active disease presented with severe colonic histological changes characterized by cellular infiltration of the lamina propria, loss of goblet cells, crypt abscesses, epithelial erosion, hyperemia, and thickening of the colonic mucosa, depletion of colitogenic CD4 T cells resulted in an overall improvement of the histological findings with progressive anti-CD4 treatment (Figure 1c,d). To track remission in intestinal inflammation in individual mice, we employed endoscopy as a widely used technique that allows for non-invasive examination of the intestine. In line with the histological analyses (Figure 1d), anti-CD4-treated mice showed greatly reduced macroscopic signs of colitis compared with mice with active intestinal inflammation (Figure 1e). Importantly, the presence of $H$. typhlonius was not a prerequisite for the onset of colitis and induction of remission in active disease but substantially affected the kinetics of disease development. Although $\mathrm{H}^{+}$ mice developed colitis upon transfer of colitogenic $\mathrm{T}$ cells within 9-12 days, colitis induction in $H$. typhlonius negative $\left(\mathrm{H}^{-}\right)$mice was significantly delayed with mice starting to show 
a

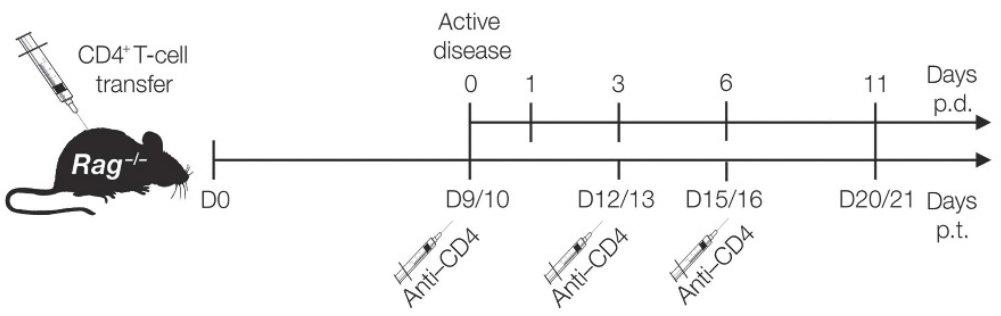

b

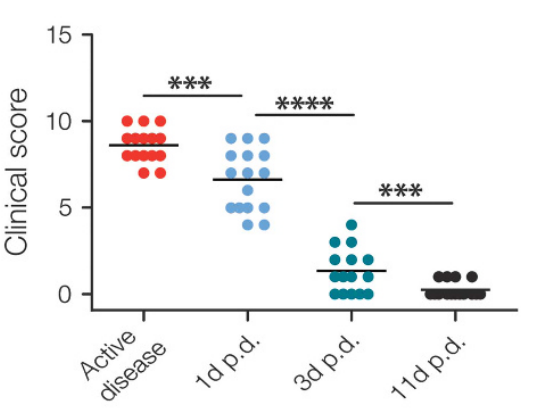

c

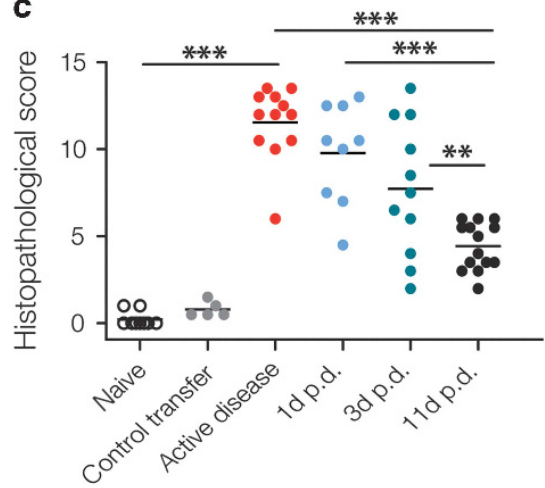

d



e

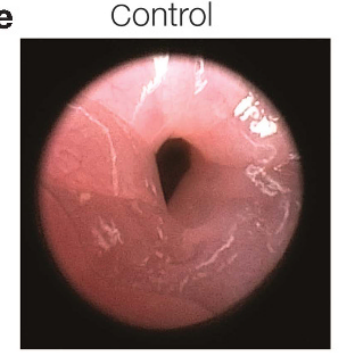

Active disease



Active disease

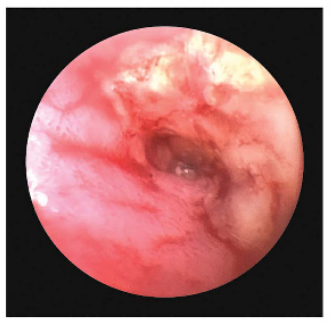

$11 d$ p.d.

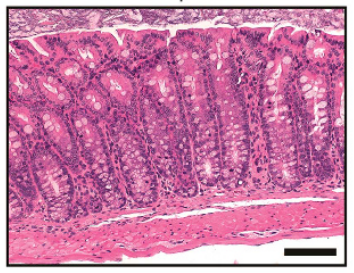

11d p.d.

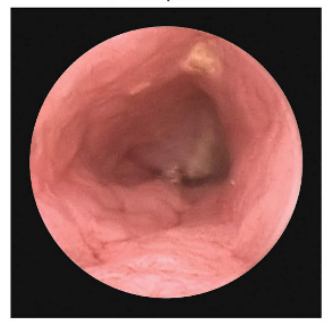

Figure 1 Depletion of colitogenic CD4 T cells rapidly induces remission in mice with intestinal inflammation. (a) Treatment protocol: Rag ${ }^{-/-} H$. typhlonius positive $\left(\mathrm{H}^{+}\right)$mice were transferred with either $2 \times 10^{5} \mathrm{CD} 4{ }^{+} \mathrm{CD} 45 \mathrm{RB}{ }^{\text {hi }} \mathrm{T}$ cells alone to induce colitis or injected with $2 \times 10^{5} \mathrm{CD} 4{ }^{+} \mathrm{CD} 45 \mathrm{RB}{ }^{\mathrm{lo}}$ $\mathrm{CD}^{2} 5^{+} \mathrm{T}$ cells as controls (control transfer). Upon induction of active intestinal inflammation (clinical scores 8-10), mice were treated with depleting CD4 antibodies (500 $\mu$ g per mouse) three times on days $9 / 10,12 / 13$, and $15 / 16$ to induce remission in colitic mice. p.d.: postdepletion; p.t.: posttransfer. (b) Clinical disease scores of mice with active intestinal inflammation and upon anti-CD4-induced remission in colitis. (c) Histopathological scores of naive mice, control transferred mice, mice with active disease, or in remission in colitis. (d) Hematoxylin and eosin staining of colonic tissue sections from control mice, mice with active disease, or mice depleted of colitogenic CD4 T cells to induce remission in colitis at day 11 after anti-CD4 depletion (p.d.). Bars $=100 \mu \mathrm{m}$. (e) Representative colonoscopy of a naive mouse prior T-cell transfer, during active colitis, or in remission in colitis (11d after anti-CD4 depletion). For $\mathbf{a}-\mathbf{d}$, pooled data from five independent experiments with $n=7-12$ mice per group are shown. For $\mathbf{e}$, representative colonoscopy of one animal with $n=3-5$ mice per group. Graphs represent mean values of individual mice. Statistics compare mice with active disease vs. mice in remission in colitis using one-way analysis of variance with Tukey's multiple comparison test; ${ }^{\star \star} P<0.01 ;{ }^{* \star} P<0.001$.

clinical signs of colitis (e.g., weight loss, diarrhea) by days $24-30$ after CD4 T-cell transfer (see Supplementary Figure S1A online). Despite different kinetics of disease onset in $\mathrm{H}^{+}$vs. $\mathrm{H}^{-}$mice, depletion of colitogenic CD4 T cells in mice with established disease promoted the induction of remission in colitis at similar kinetics irrespective of the colonization status of mice (see Supplementary Figure S1B,C). Furthermore, infection with $H$. typhlonius by oral gavage of live bacteria did not result in significant alterations of local and systemic immune responses as assessed at different time points after infection and compared with mice permanently colonized with $\mathrm{H}^{+}$or $\mathrm{H}^{+}$mice with active colitis (see Supplementary Figure S2A-C). Given the accelerated and highly predictable kinetics of colitis induction in $\mathrm{H}^{+}$mice, we decided to use 

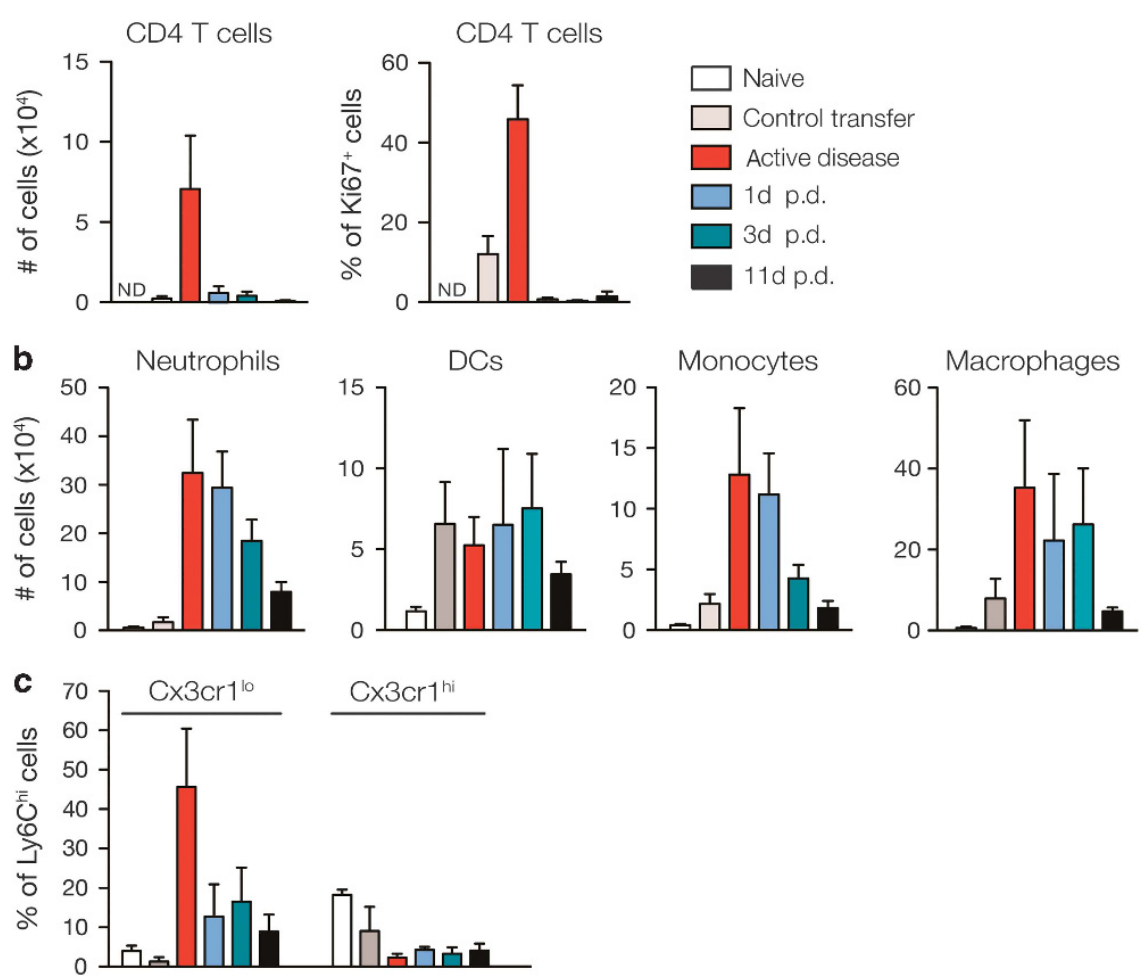

Figure 2 Reduced colonic cellular immune infiltration in response to treatment-induced remission in colitis. (a) Total numbers of infiltrating CD4 T cells and frequencies of proliferating CD4 T cells in the colon of control $\mathrm{H}^{+} \mathrm{Rag}^{-/-}$mice, mice with active disease, or mice in remission in colitis at the indicated time points after first anti-CD4 depletion. (b) Total numbers of infiltrating neutrophils, dendritic cells (DCs), monocytes, and macrophages in the colon. (c) Frequencies of $\mathrm{C} \times 3 \mathrm{Cr}^{\mathrm{lo}}{ }^{\mathrm{C}}$ (pro-inflammatory) and Cx3cr1 ${ }^{\text {hi }}$ (resident) $\mathrm{Ly}_{6 \mathrm{c}}{ }^{+}$monocyte/macrophage cell populations in the colon of CD4 T-cell transferred

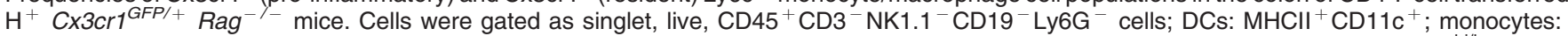

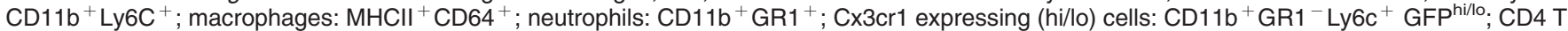
cells: singlet, live, $\mathrm{CD} 45^{+} \mathrm{CD} 4{ }^{+} \mathrm{TCR} \alpha \beta^{+} \mathrm{CD} 3^{+}$. Pooled data from four independent experiments with $n=7-10$ mice per group are shown. ${ }^{*} P<0.05$; ${ }^{* *} P<0.01$.

$\mathrm{H}^{+}$recipients that reproducibly and progressively lose $10-15 \%$ of their initial body weight between days 9-12 upon adoptive transfer of colitogenic CD4 T cells. Together, these data indicate that depletion of colitogenic $\mathrm{CD} 4 \mathrm{~T}$ cells in mice with established disease resulted in the suppression of active intestinal inflammation and the induction of mucosal healing as assessed by clinical and histological disease parameters.

\section{Reduced cellular infiltration to sites of inflammation in response to treatment-induced remission in colitis}

Infiltration of the intestinal mucosa by immune cells is a critical hallmark and causative of IBD. ${ }^{19-21}$ To examine the distribution of infiltrating cells to sites of inflammation during active disease and upon treatment-induced remission in colitis, we employed a flow cytometric approach. Upon adoptive transfer of $\mathrm{CD} 4{ }^{+} \mathrm{CD} 45 \mathrm{RB}^{\mathrm{hi}} \mathrm{T}$ cells into lymphopenic hosts, colitogenic $\mathrm{CD} 4 \mathrm{~T}$ cells infiltrate and proliferate in the large intestine (Figure 2a). In line with local expansion and accumulation of colitogenic CD4 T cells, we observed the infiltration of neutrophils, monocytes, macrophages, and dendritic cells to colonic tissues of mice with active disease (Figure $\mathbf{2 b}, \mathbf{c}$ ). Next, we tested whether therapeutic administration of anti-CD4 antibodies is associated with reduced leukocyte infiltration to the sites of intestinal inflammation. Anti-CD4 treatment of mice with established disease resulted in a rapid and efficient depletion of CD4 T cells from the small and large intestine, the spleen, and the blood (Figure 2a, and data not shown). Importantly, few $\mathrm{CD} 4 \mathrm{~T}$ cells with low proliferative capacity as demonstrated by Ki67 staining persist in the intestinal tract (Figure 2a) upon anti-CD4 treatment. Although depletion of colitogenic $\mathrm{CD} 4 \mathrm{~T}$ cells results in remission from colitis 11 days after first antibody treatment, colonic inflammation is relapsing starting around days 22-25 after first depletion if mice in remission are not continuously treated with anti-CD4 antibodies beyond day 11 (see Supplementary Figure S3). This further allows studying mechanisms operative during different phases of relapsing-remitting colitis. In line with a reduction in clinical and histological disease scores (Figure 1b,c), depletion of colitogenic CD4 $\mathrm{T}$ cells was paralleled by a reduced recruitment of neutrophils and monocytes to sites of inflammation and a blunted local expansion of macrophages in the large intestine (Figure 2b). Using $\mathrm{Cx} 3 \mathrm{cr} 1^{\mathrm{GFP} /+}$ mice, we demonstrated that the majority of macrophages in the inflamed colon consisted of infiltrated inflammatory macrophages $\left(\mathrm{Cx} 3 \mathrm{cr}^{\mathrm{lo}}\right)$, which decreased rapidly upon anti-CD4 treatment, while the frequencies of 
resident $\left(\mathrm{Cx} 3 \mathrm{crr}^{\mathrm{hi}}\right)$ macrophages did not change in response to induction of remission compared with mice with active disease (Figure 2c). Together, these data demonstrate that depletion of colitogenic CD4 $\mathrm{T}$ cells in mice with established disease was associated with a rapid reduction in the infiltration of immune cells to sites of inflammation with alterations in the local composition of the macrophage compartment.

\section{Treatment-induced remission in colitis alters intestinal gene expression profiles}

In addition to our analyses of cellular responses (Figure 2), we aimed to gain more insight into molecular processes during the different disease stages of colitis. Therefore, we evaluated gene expression profiles in whole colonic tissue samples derived from control mice, mice with active disease, and mice in remission on days 1, 3, and 11 after anti-CD4 treatment, employing custommade RT Profiler PCR arrays. Values obtained were normalized with the corresponding values from anti-CD4-treated lymphopenic mice transferred with $\mathrm{CD}^{+} \mathrm{CD}^{+} 5 \mathrm{RB}^{\text {lo }}$ CD25 ${ }^{+} \mathrm{T}$ cells and thus do not develop colitis. In line with a reduced infiltration of immune cells to the colonic mucosa of colitic mice in response to anti-CD4 treatment, treatmentinduced remission was associated with significant changes in colonic gene expression profiles (Figure 3). Although mice with active disease presented with elevated expression levels of proinflammatory mediators, including Ifng, Il1a, Il1b, Il6, Trem1, Il33, Tnfa, Ill7a, and Ill7f, treatment-induced remission correlated with a rapid reduction in the expression levels of these genes over time. Further, remission in colitis was associated with a reduction in chemokines, including $\mathrm{Ccl} 2$, Ccl3, Cxcl1, Cxcl2, and Cxcl10, compared with mice with active disease. In order to corroborate the impact of $H$. typhlonius colonization in our model system, mRNA expression and/or protein levels were assessed in $\mathrm{H}^{-}$and $\mathrm{H}^{+}$mice with comparable colonic levels of pro- and anti-inflammatory mediators, chemokines, and IEC-related responses (see Supplementary Figure S4A,B). Together with alterations in the cellular content in the large intestine in mice with active intestinal inflammation vs. remission (Figure 2a-c), these data provide a comprehensive analysis comparing colonic gene expression profiles of mice with active disease and mice in different stages of remission.

\section{Remission in colitis is associated with a rapid regeneration of the colonic mucus layer}

The intestinal epithelium and its covering mucus layer represent important barriers that limit microbial leakage into the underlying lamina propria. ${ }^{3,4}$ Targeted genetic manipulation of key components of the mucus layer in animal models have been associated with weakening of the protective function of the intestinal mucus layer and the development of bacterialinduced intestinal inflammation. ${ }^{22,23}$ The concept of the mucus layer functioning as a highly dynamic protective barrier was demonstrated in intestinal inflammatory conditions in which altered goblet cell responses promote enhanced mucus secretion to avoid direct microbial exposure to IECs. ${ }^{24,25}$ In

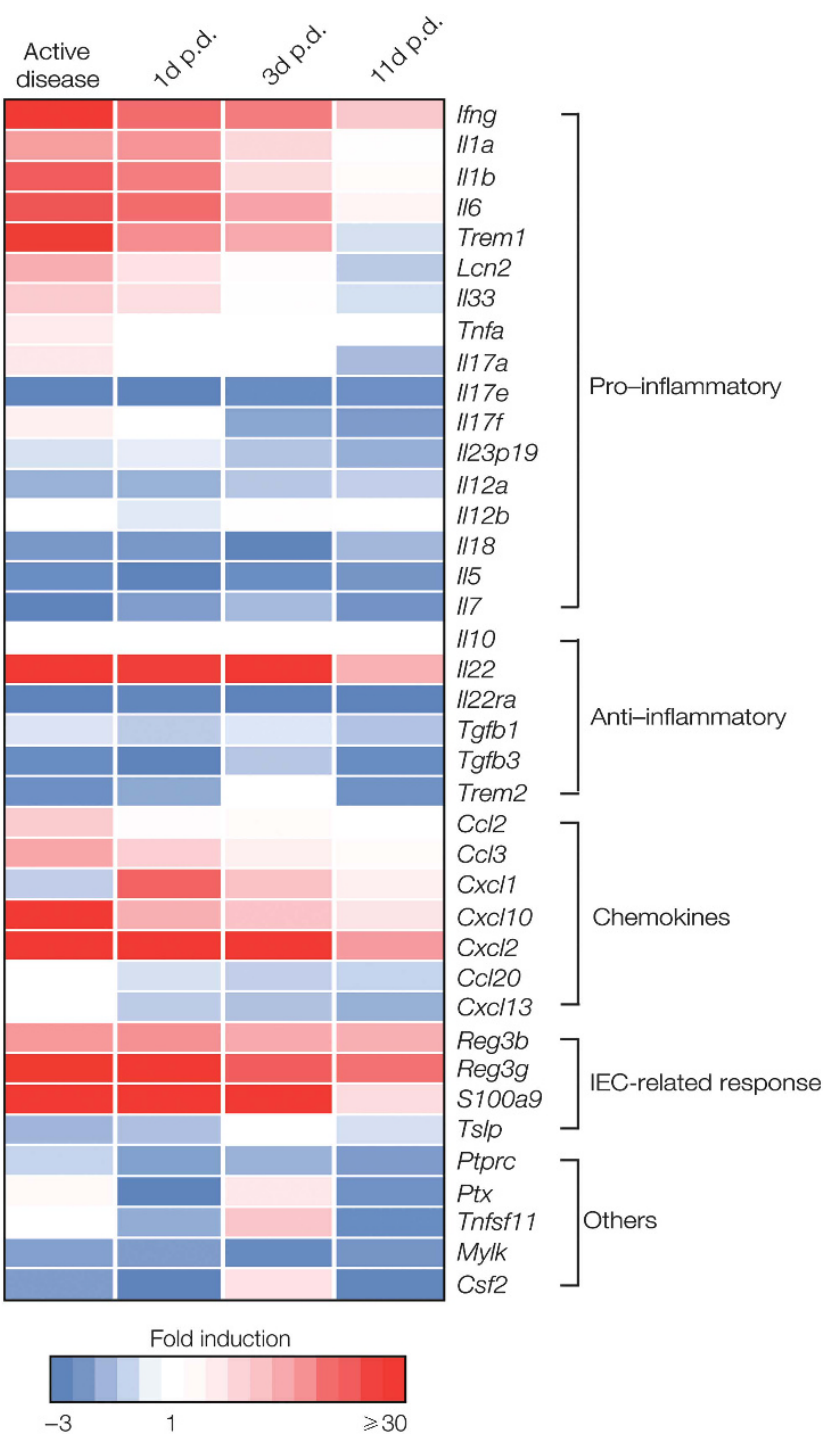

Figure 3 Treatment-induced remission in colitic mice alters intestinal gene expression profiles. Heat-map representing colonic gene expression profiles of pro- and anti-inflammatory mediators, chemokines, intestinal epithelial cell (IEC)-related response genes, and others in $\mathrm{Rag}^{-1-} \mathrm{H}^{+}$ mice with active intestinal inflammation or mice treated with anti-CD4 antibodies at days 1,3 , and 11 postdepletion (p.d) to induce remission in colitis. RNA values were normalized to the endogenous control genes Gapdh and $\beta 2$-microglobulin and presented as fold induction/reduction over mice that were transferred with $\mathrm{CD} 4^{+} \mathrm{CD}_{45 \mathrm{RB}^{10}} \mathrm{CD}_{2} 5^{+} \mathrm{T}$ cell and subsequently depleted of CD4 T cells on day 11 p.t. Pooled data from four independent experiments with $n=5-8$ mice per group are shown.

IBD, however, the mucus layer is compromised likely due to a loss of function of mucus-secreting goblet cells favoring the penetration of microbes to the intestinal mucosa causing uncontrolled immune cell activation and tissue damage. ${ }^{26,27} \mathrm{To}$ study the dynamics of the mucus layer in response to active intestinal inflammation and upon induction of remission we isolated colonic tissue samples from either naïve control mice, mice with active disease or mice in remission. To visualize the structure of the mucus layer, we either stained colonic tissue sections with periodic-acid Schiff or antibodies specific for Muc-2, a major component of the intestinal mucus layer in 
a
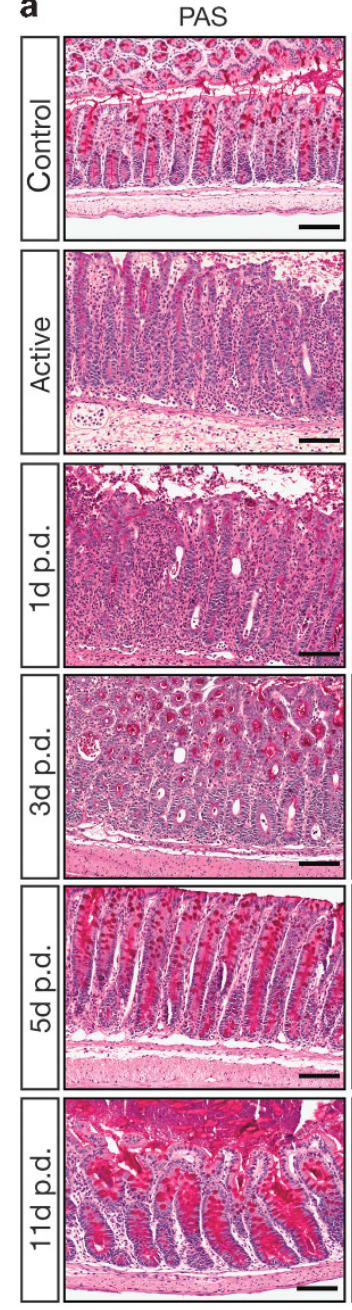

b

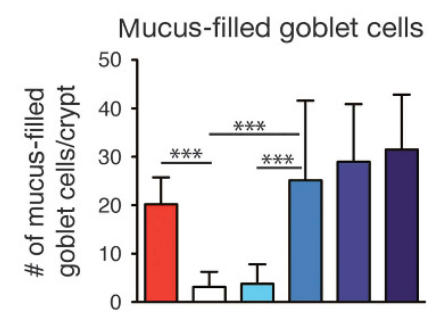

Muc2
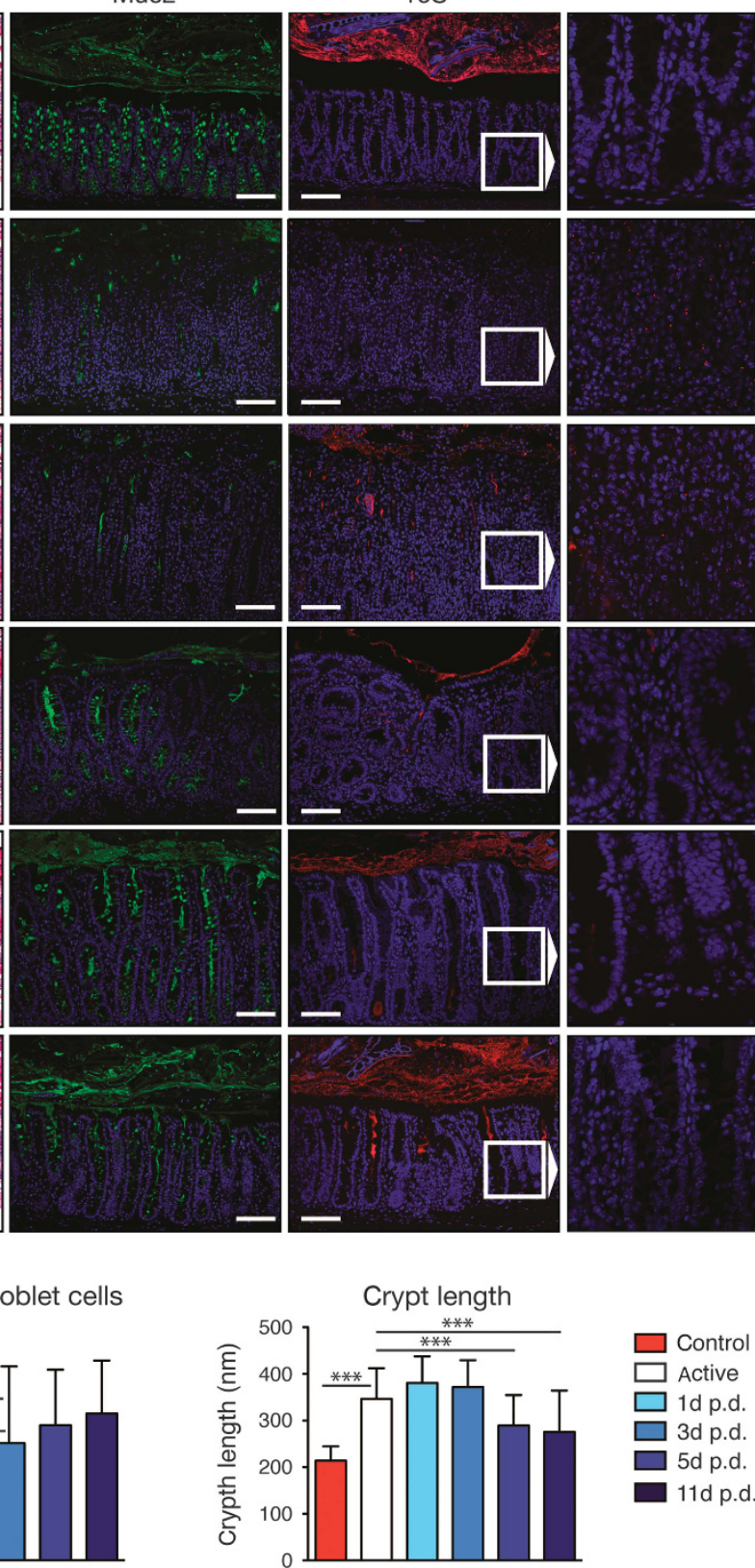

Figure 4 Restoration of colonic mucus layer in response to depletion of colitogenic CD4 T cells and associated mucosal healing. (a) Periodic acid-Schiff staining (PAS), Muc-2 staining and 16S rRNA in situ hybridization of colonic tissue sections from naive control Rag ${ }^{-/-} \mathrm{H}^{+}$mice, mice with active disease, or mice depleted of colitogenic CD4 T cells to induce remission in colitis on days 1, 3, 5, and 11 after anti-CD4 depletion (postdepletion (p.d.)). Bars $=100 \mu \mathrm{m}$. (b) Goblet cells per crypt and crypt length measured on Alcian blue2.5/PAS-stained Carnoy-fixed tissue sections of the transverse colon of naive control mice, mice with active disease, or mice in remission in colitis on days 1,3, and 11 days after anti-CD4 depletion. Data from three independent experiments quantifying three consecutive intermediate sections per colon are shown. $n=3-4$ mice per group and experiment. Statistics compare healthy controls vs. mice with active disease vs. mice in remission in colitis using one-way analysis of variance with Tukey's multiple comparison test. ${ }^{\star} P<0.05 ;{ }^{* \star} P<0.01 ;{ }^{* \star *} P<0.005$.

mice (Figure 4a). Although the mucus layer in colitic mice was completely compromised, treatment-induced remission was associated with an increased proliferation of colonic epithelial cells as demonstrated by anti-Ki67 staining (see Supplementary Figure S5) and associated restoration of the mucus layer, most likely owing to a rapid recovery of goblet cell function in response to mucosal healing (Figure $4 \mathbf{b}$ ).
Intestinal epithelial erosion is a hallmark of IBD resulting in translocation of commensal bacteria to the underlying mucosa and uncontrolled activation of immune cells promoting immune-mediated tissue damage. ${ }^{28}$ In addition to demonstrating the restoration of the colonic mucus layer in response to mucosal healing, we performed in situ hybridization to study the spatial distribution of bacteria in colonic tissue sections 
during the different stages of disease. To do so, we employed the fluorescent-labeled rRNA probe of conserved bacterial rRNA regions (eubacterial probe EUB338, 16S) for hybridization. Using this technique, we demonstrate that mice with active colitis had clear signs of bacterial dissemination to the intestinal mucosa (Figure 4a, 16S). In contrast, the regeneration of the mucus layer in response to treatment-induced remission correlated with a restored physical separation of commensal bacteria and the intestinal epithelial layer.

\section{Restoration of intestinal epithelial barrier integrity in response to depletion of colitogenic CD4 T cells}

Pro-inflammatory cytokines, including TNF $\alpha, \operatorname{IL} 1 \alpha$, IL $1 \beta$, and IL6, critically participate in the inflammatory cascade in IBD, which includes barrier disruption. ${ }^{29,30}$ In the present study, active colitis was associated with strong systemic TNF $\alpha$ responses that were quickly abrogated upon depletion of colitogenic CD4 $\mathrm{T}$ cells in mice with established disease (Figure 5a). In line with a decrease in systemic (Figure 5a) and colonic TNF $\alpha$ levels (Figure 3, see Supplementary Figure S4), fecal lipocalin-2, a sensitive non-invasive biomarker for intestinal inflammation, was reduced in response to treatment-induced remission (Figure 5b). In order to test whether the observed downregulation of local and systemic pro-inflammatory mediators were associated with a restoration of intestinal epithelial barrier integrity, we measured albumin levels in the feces of mice in different disease stages. Consistent with previous studies, fecal albumin levels were elevated in mice with active disease. ${ }^{31}$ In response to anti-CD4 treatment, fecal albumin levels gradually decreased with time and repetitive anti-CD4 treatment reaching levels of healthy mice 11 days after depletion of colitogenic CD4 T cells. These data suggest that treatment-induced remission is associated with the restoration of intestinal epithelial barrier integrity in this model system (Figure 5c).

$\mathrm{TNF} \alpha$ is an important mediator of acute and chronic intestinal inflammatory disorders and treatment with monoclonal antibodies against TNF $\alpha$ has been proven to induce and maintain clinical remission in many patients with IBD. As in our model active colitis was associated with strong local and systemic $\mathrm{TNF} \alpha$ responses that were rapidly abrogated upon anti-CD4 treatment (see Supplementary Figure S4B, Figure 5a), we tested whether the remitting effect of antiCD4 treatment can be attributed to the observed reduction in local and systemic TNF $\alpha$. However, in contrast to anti-CD4 treatment, neutralization of $\mathrm{TNF} \alpha$ in mice with established colitis failed to induce remission and mucosal healing as assessed by weight loss and reflected histopathological disease scores (Figure 5d,f). Importantly, local and systemic proinflammatory cytokines, chemokines, and growth factors were not significantly affected by anti-TNF $\alpha$ treatment, suggesting that in active colitis other pro-inflammatory mediators may compensate for abrogated TNF $\alpha$ bioactivity and maintenance of active colitis (Figure 6a,b). Intriguingly, while anti-TNF $\alpha$ treatment was initiated prior to colitis induction, mice were fully protected from disease as reflected in a lack of body weight loss (Figure 5e) and low levels of local and systemic proinflammatory mediators despite transfer of colitogenic CD4 T cells (Figure 6a,b). Collectively, we carefully characterized a new experimental model of treatment-induced remission in mice with colitis that will allow to further study the dynamics of mucosal healing in the context of chronic intestinal remittingrelapsing disorders in a highly reproducible mouse model system.

\section{DISCUSSION}

Substantial progress has been made in the past to develop mouse models of acute and chronic intestinal inflammation. These experimental models were of utmost importance to decipher different aspects in the pathogenesis of IBD (Crohn's disease (CD), ulcerative colitis (UC)). UC and CD typically have an unpredictable relapsing-remitting chronic course while the molecular and cellular events causing remission in IBD are still incompletely understood. ${ }^{32}$ Despite numerous animal models mimicking IBD in humans, few experimental models allow for studying cellular and molecular mechanisms of mucosal healing associated with remission. Importantly, in patients with IBD the early induction of mucosal healing on endoscopy predicts clinical remission in patients with $\mathrm{CD}^{33}$ and $\mathrm{UC}^{34}$ and a better disease control, more frequent steroid-free remission of disease, longer resection-free intervals, and improved quality of live. Given the relevance of mucosal healing as a new treatment goal in IBD management, there is an urgent need to develop new animal models to study cellular and molecular pathways involved in early stages of remission in mice with active colitis.

Previous studies demonstrated that remission in experimental colitis could be induced by adoptive transfer of Tregs, ${ }^{17}$ administration of DSS, followed by maintenance on normal drinking water, ${ }^{35}$ administration of TNF $\alpha$ antibodies, ${ }^{36}$ or antibiotics to mice with active disease. ${ }^{37}$ One major disadvantage of previously described remitting models of colitis is the unpredictable timing and extent of remission induction. Hence, we attempted to establish a new mouse model of reversible $\mathrm{T}$-cell colitis that allows for defined and highly reproducible kinetics of remission induction. Employing this model system, we assessed the kinetics of mucosal healing using different parameters, including clinical, histopathological, and endoscopic measures (Figure 1), analysis of cellular infiltrates (Figure 2), colonic gene expression profiles of pro- and antiinflammatory mediators (Figure 3), reconstitution of the colonic mucus layer (Figure 4), increased proliferation of epithelial cells (see Supplementary Figure 5), and associated re-establishment of intestinal barrier integrity (Figure 5) in response to treatment-induced remission in colitis. Using $\mathrm{H}^{+}$ $\mathrm{Rag}^{-/-}$mice that, upon transfer of colitogenic CD4 T cells, develop a progressive colitis with clinical signs of disease starting between day 9 and 12 after CD4 T-cell transfer (Figure 1a), we demonstrate that administration of depleting CD4 antibodies to mice with established colitis was associated with a rapid improvement in clinical signs as early as $24 \mathrm{~h}$ after first antibody treatment (Figure 1b). Anti-CD4 treatment was 


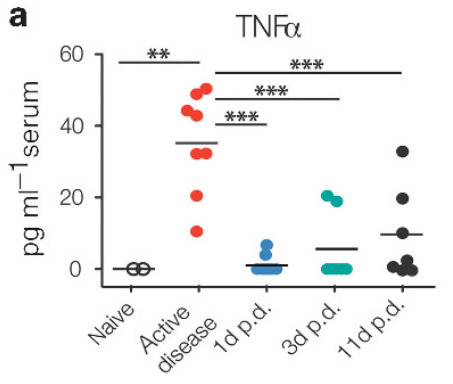

d
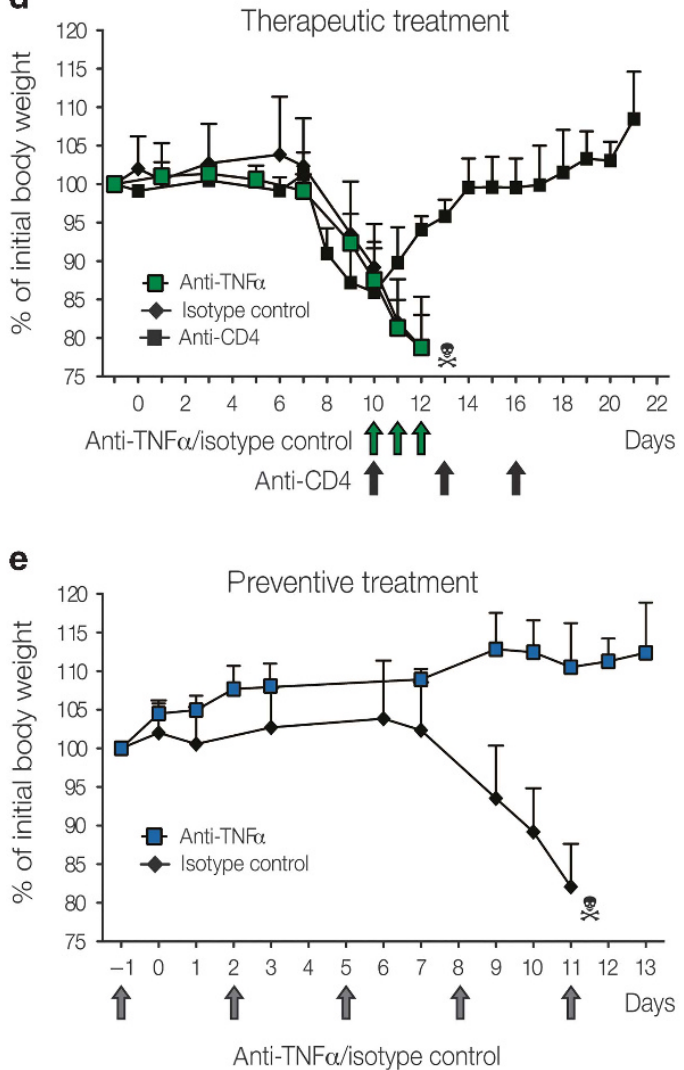

Anti-TNF $\alpha$ /isotype control
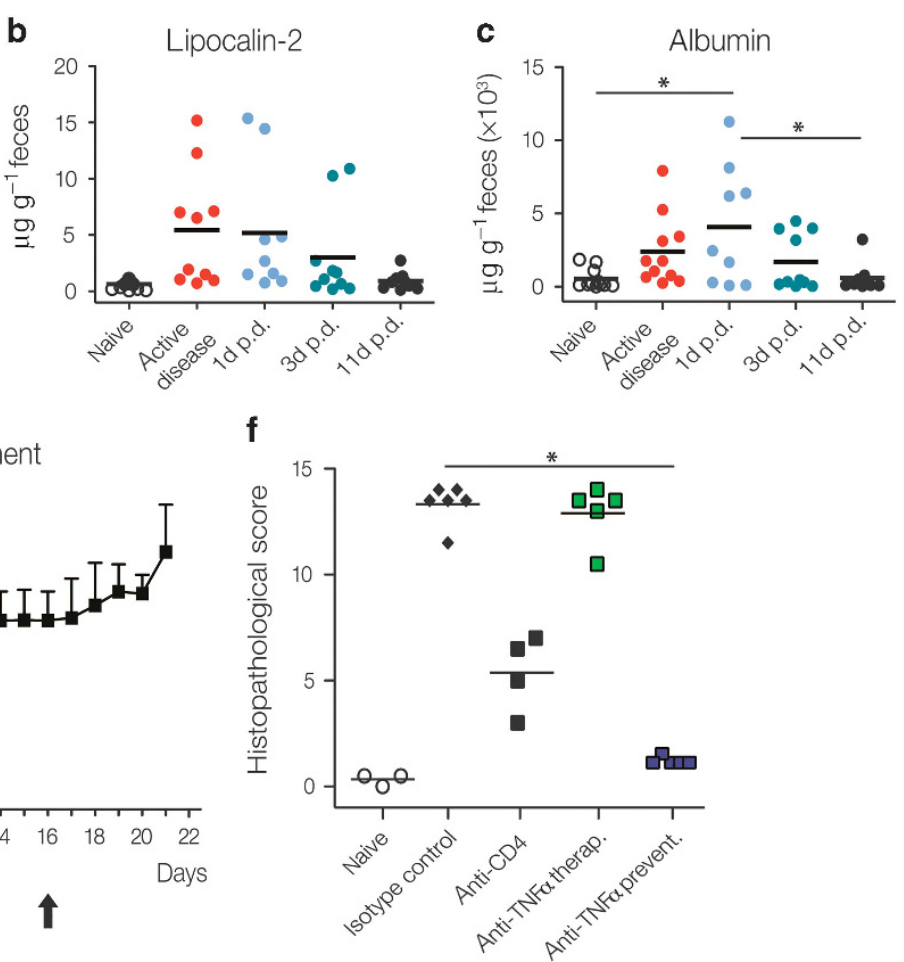

Figure 5 Restoration of intestinal epithelial barrier integrity in response to treatment-induced remission in mice with colitis and contribution of tumor necrosis factor $\alpha(T N F)$ in colitis induction and progression. (a) Serum TNF $\alpha$ protein levels in naive $\mathrm{Rag}^{-/-} \mathrm{H}^{+}$mice, mice with active disease, or mice in remission in colitis on days 1, 3, and 11 days after anti-CD4 depletion (postdepletion (p.d.)). (b) Fecal lipocalin-2. (c) Fecal albumin. Pooled data from 5 independent experiments with $n=2-11$ mice per group are shown. Graphs represent mean values of individual mice. Statistics compare naive controls vs. mice with active disease vs. mice in remission using one-way nalysis of variance with Tukey's multiple comparison test. ${ }^{*} P<0.05$; ${ }^{* \star} P<0.01$; ${ }^{* \star \star} P<0.001$. (d,e) Percentage of body weight change in response to (d) therapeutic or (e) preventive anti-TNF $\alpha$ treatment compared with anti-CD4 therapeutic treatment. (f) Colonic histopathology scores of naive $\mathrm{H}^{+} \mathrm{Rag}^{-\prime-}$ mice compared with mice that were treated with anti-TNF $\alpha$ prior colitis induction (prevent.), mice with active disease treated with anti-TNF $\alpha$ (therap., green arrows), or mice with active disease treated with anti-CD4 antibodies (black arrows) at the indicated time points. Data with $n=4-6$ mice per group are shown.

further associated with a significant reduction in the frequencies and total numbers of infiltrating neutrophils and macrophages to sites of inflammation (Figure 2) as well as a decrease in colonic expression levels of proinflammatory mediators (Figure 3), resulting in clinical and histopathological remission in active colitis in response to repetitive anti-CD4 treatment (Figure 1).

Infection or colonization of lymphopenic mice with Helicobacter spp. has been demonstrated to have diseaseaccelerating properties in response to T-cell-mediated transfer colitis. ${ }^{38}$ As such, Helicobacter hepaticus infection is sufficient to promote spontaneous colitis in mice on an IL-10-deficient background, highlighting the importance of Helicobacter on colitis pathogenesis. ${ }^{39}$ We employed here either $H$. typhloniusnegative $\left(\mathrm{H}^{-}\right)$or $H$. typhlonius-positive $\left(\mathrm{H}^{+}\right)$mice for studying disease kinetics of CD4 T-cell-mediated transfer colitis. Although H. typhlonius colonization was not a prerequisite for the onset of colitis and induction of remission in active disease, the presence of $H$. typhlonius substantially accelerated the kinetics of disease development compared with 
a

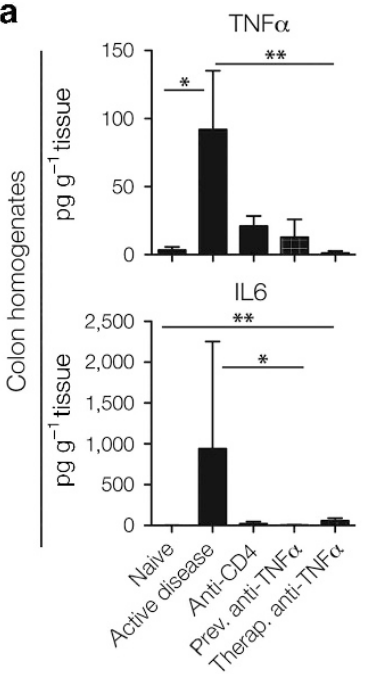

b

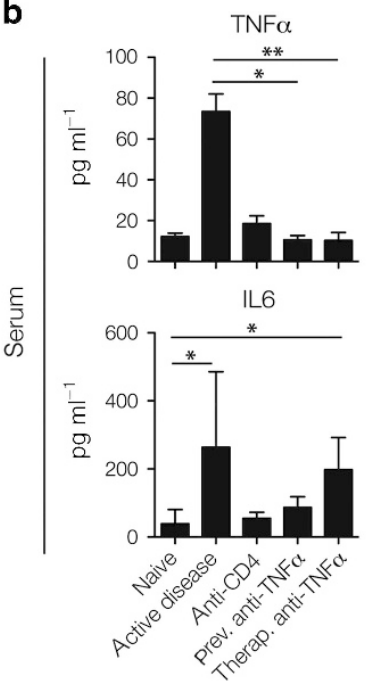

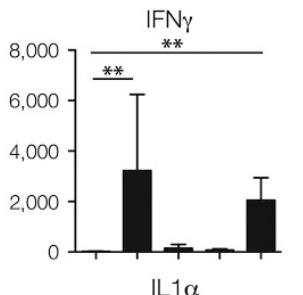
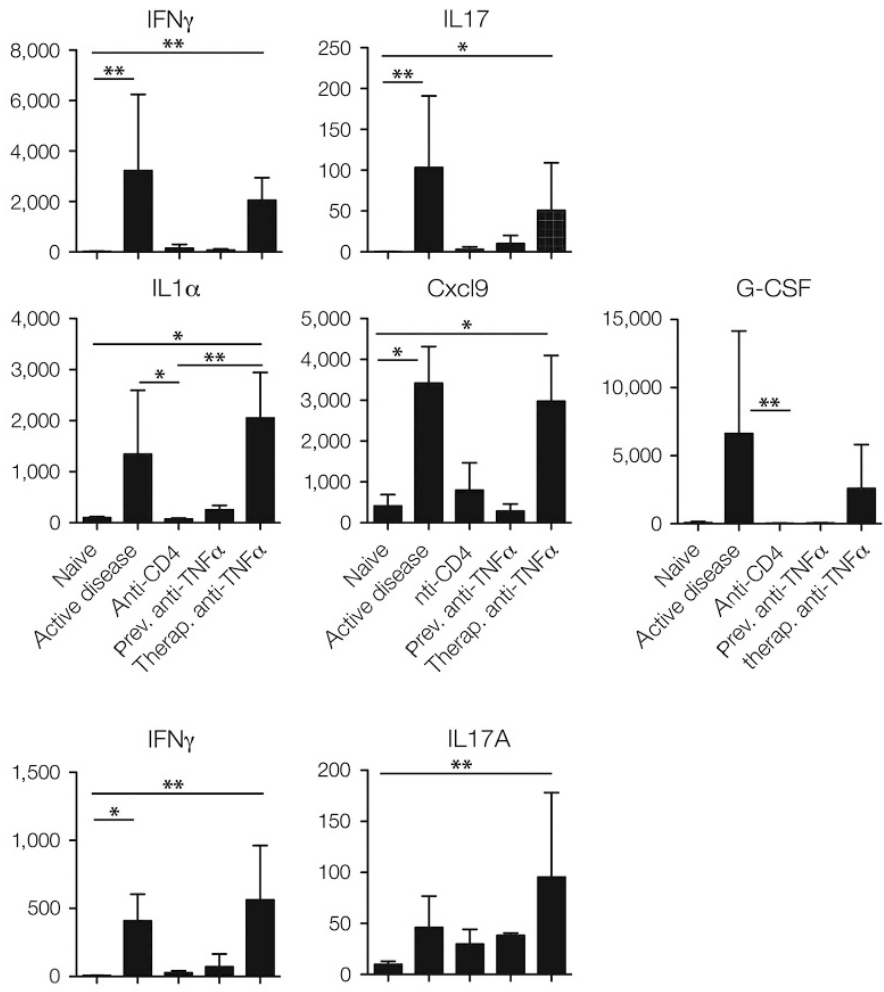

$\operatorname{IL} 1 \alpha$

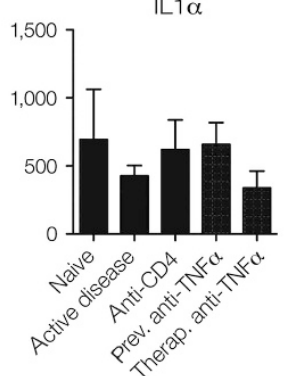

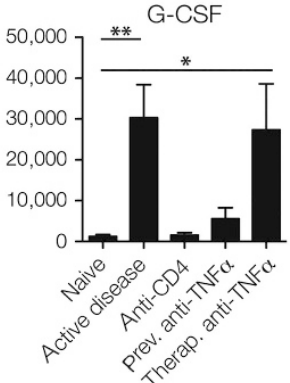

Figure 6 Neutralization of tumor necrosis factor $\alpha(T N F \alpha)$ during active colitis does not alter concentrations of other pro-inflammatory mediators. Protein levels for TNF $\alpha$, interferon- $\gamma$ (IFN $\gamma$ ), interleukin-17A (IL17A), IL6, IL1 $\alpha$, C-X-C chemokine ligand 9 (Cxcl9), and ganulocyte colony-stimulating factor (G-CSF) in (a) colon homogenates and (b) sera of $\mathrm{H}^{+}$Rag $^{-/-}$mice. $\mathrm{H}^{+}$Rag $^{-1-}$ mice were transferred with colitogenic $\mathrm{CD}^{+} \mathrm{CD}^{+} 5 \mathrm{RB}^{\mathrm{hi}} \mathrm{T}$ cells to induce colitis and either treated with anti-TNF $\alpha$ prior to transfer of colitogenic T cells (preventive treatment), during active disease with anti-TNF $\alpha$ (therapeutic treatment), or with anti-CD4 to induce remission. Mice were analyzed on days 12/13 after transfer (active disease and preventive anti-TNF $\alpha$ ), on day 4 after treatment (therapeutic anti-TNF $\alpha$ ), and on day 11 after depletion (anti-CD4). Serum and colon homogenate samples were analyzd by bead-based multiplex assay for cytokines. Mean values \pm s.d. are shown from pooled data of two independent experiments with $n=4-6$ mice per group. Statistics compare the different groups using one-way analysis of variance with Dunn's multiple comparison test. ${ }^{\star} P<0.05$; ${ }^{* \star} P<0.01$. Prev, preventive; Therap, therapeutic.

$\mathrm{H}^{-}$recipients (see Supplementary Figure S1A). Importantly, induction of remission in colitis occurred at similar kinetics irrespective of H. typhlonius colonization (see Supplementary Figure 1B,C). Despite accelerated disease kinetics, colonic gene expression profiles and protein levels of pro-inflammatory mediators were comparable in $\mathrm{H}^{-}$and $\mathrm{H}^{+}$mice with active disease (see Supplementary Figure S3A,B). Because of the accelerated and highly predictable kinetics of colitis induction in $\mathrm{H}^{+}$mice, we used $\mathrm{H}^{+}$recipients that reproducibly and progressively lose $10-15 \%$ of their initial body weight between days 9-12 after adoptive T-cell transfer. Given that oral gavage of $\mathrm{H}^{-} \mathrm{Rag}^{-/-}$mice with live $\mathrm{H}$. typhlonius did not promote local and systemic immune responses despite the establishment of a permanent $\mathrm{H}^{+}$colonization (see Supplementary Figure S2A-C), $\mathrm{H}^{-}$mice or $\mathrm{H}^{-}$breeder colonies can be easily and reliably colonized with commercially available $H$. typhlonius isolates prior to induction of reversible T-cell-mediated transfer colitis.

$\mathrm{CD}^{+}$innate lymphoid cells (ILCs) are critical for promoting immunity in the intestine by their secretion of IL-22 that induces the expression of antimicrobial peptides and promotes the maintenance of the epithelial barrier integrity. ${ }^{40}$ Given that in our model CD4 ${ }^{+}$ILCs may also get depleted, we used a T-cell-specific depletion regimen to rule out an antiCD4-mediated depletion of CD4 ${ }^{+}$ILCs by transferring Thy 1.2 congenic $\mathrm{T}$ cells into Thyl.1 lymphopenic hosts to further 
corroborate the finding of a strict CD4 T-cell-dependent maintenance of colitis. This experimental approach allowed us to study and compare the role of $\mathrm{CD} 4 \mathrm{~T}$ cells in colitis induction and maintenance of disease in the absence or preserved presence of $\mathrm{CD}^{+}{ }^{+}$ILCs. Employing anti-Thy1.2-mediated T-cell depletion, we demonstrate that depletion of colitogenic $\mathrm{T}$ cells in the preserved presence of $\mathrm{CD} 4{ }^{+}$ILCs resulted in rapid remission in active colitis comparable to remission induction in mice depleted of $\mathrm{CD}^{+}$-expressing cells (see Supplementary Figure S7A-D). Collectively, these data suggest that endogenous $\mathrm{CD}^{+}{ }^{+}$ILCs do not significantly contribute to mucosal healing in this model system.

Although it has been reported that microbial stimulation of innate immune cells and activation of $\mathrm{T}$ cells by their cognate microbial antigen are both required for the development of T-cell-mediated transfer colitis, ${ }^{41}$ we here demonstrate for the first time that colitogenic CD4 T cells are not only necessary for colitis induction but also essential for maintenance of disease (Figure 1). These results are rather surprising implicating that disruption of the intestinal barrier integrity associated with an uncontrolled stimulation of the innate immune system by luminal antigens is not sufficient for continuous recruitment of pro-inflammatory innate immune cells to sites of inflammation in the absence of colitogenic $\mathrm{T}$ cells in this colitis model. In order to investigate how colitogenic $\mathrm{CD} 4 \mathrm{~T}$ cells promote the continuous infiltration of innate immune cells to sites of inflammation, we targeted $\mathrm{T}$ cell-antigen-presenting cell interactions by means of anti-CD40L treatment. However, blocking CD40L-CD40 interactions did not have a diseaseameliorating effect in mice with established disease (see Supplementary Figure S6A,B). These data are in line with a previous study demonstrating that blocking CD40L-CD40 interactions in the CD4 $\mathrm{T}$ cell transfer model of colitis was not sufficient to ameliorate disease in mice with established colitis. ${ }^{42}$ Therefore, continuous stimulation of innate immune cells by colitogenic $\mathrm{CD} 4 \mathrm{~T}$ cells may be a prerequisite for maintenance of disease. However, additional experiments are required to assess whether blocking $\mathrm{T}$ cell-antigen-presenting cell interactions are not sufficient to promote remission in disease in the transfer colitis model.

Next, we wanted to investigate whether a T-cell-derived factor for intestinal mononuclear phagocyte recruitment and differentiation was necessary for continued intestinal inflammation. Blocking granulocyte-macrophages colony-stimulating factor (GM-CSF) reduces the accumulation of splenic and colonic granulocyte-monocyte progenitors, resulting in amelioration of transfer colitis, ${ }^{41,42}$ and as activated T cells are a major source of GM-CSF, we analyzed colonic GM-CSF levels in control mice, mice with active disease, and mice in remission upon depletion of colitogenic $\mathrm{T}$ cells. Although colonic GM-CSF levels were elevated in mice with active disease, depletion of CD4 T cells resulted in a significant drop in colonic GM-CSF levels (data not shown). Thus, consistent with the Griseri study, a reduction of GM-CSF levels in response to depletion of $\mathrm{CD} 4 \mathrm{~T}$ cells was associated with an amelioration of disease in our model system.
Treatment with TNF $\alpha$-specific agents represents an important cornerstone in current clinical therapy of immune-mediated diseases, including $\mathrm{CD}$ and UC. Monoclonal antibodies directed against soluble and membrane-bound TNF $\alpha$ such as infliximab or adalimumab not only block TNF $\alpha$ signaling but may also have the capacity to mediate depletion of the TNF $\alpha$-producing cells by complement-dependent cytotoxicity, antibody-dependent cellmediated cytotoxicity, or apoptosis induction. ${ }^{43}$ Given the elevated systemic TNF $\alpha$ levels observed in our animal model that significantly dropped upon depletion of colitogenic $\mathrm{T}$ cells (Figure 5a) and the efficacy of anti-TNF $\alpha$ treatment for induction and maintenance of clinical remission in IBD, we tested whether blocking uncontrolled $\mathrm{TNF} \alpha$ signaling is sufficient to induce remission. Although depletion of colitogenic CD4 $\mathrm{T}$ cells in mice with established disease rapidly induced remission in active colitis, treatment of colitic mice with antibodies against $\mathrm{TNF} \alpha$ failed to attenuate intestinal inflammation and animals had to be killed owing to progressive weight loss and diarrhea (Figure 5d,f). Intriguingly, while treatment of human peripheral blood leukocytes and activated lamina propria cells isolated from patients with $\mathrm{CD}$ with the monoclonal TNF $\alpha$ antibody infliximab was reported to lead to a marked apoptosis induction in CD4 T cells, ${ }^{44}$ we did not find indications for a cell-depleting effect in anti-TNF $\alpha$-treated mice as assessed by flow cytometric analysis of immune cell frequencies in colonic tissues, peripheral blood, and mesenteric lymph nodes (data not shown). Furthermore, while TNF $\alpha$ concentrations in the colon and serum of colitic mice were efficiently reduced upon anti-TNF $\alpha$ treatment, mRNA expression levels for TNF $\alpha$ in whole colonic tissue remained unaffected (data not shown).

Remarkably, concentrations of other pro-inflammatory mediators in the serum and colonic tissue of colitic mice were not affected by anti TNF $\alpha$ treatment, thus indicating that these mediators may compensate for the absence of TNF $\alpha$ bioactivity and thus mediate exacerbation of the disease. Previous animal studies reported a therapeutic effect of antiTNF $\alpha$ treatment. ${ }^{37}$ These discrepant findings may be attributed to the extent of intestinal inflammation present when anti$\mathrm{TNF} \alpha$ treatment was initiated. Indeed, when, in line with previous studies, ${ }^{22}$ administration of anti-TNF $\alpha$ mAb was initiated together with the adoptive transfer of colitogenic $\mathrm{T}$ cells, $\mathrm{H}^{+} \mathrm{Rag}^{-/-}$recipients were fully protected from T-cellmediated colitis. (Figure 5e).

The observed changes in the dynamics of mucus layer formation throughout induction of colitis and its recovery during remission are remarkable (Figure 4) as alterations in the formation of the mucus layer have been associated with IBD, in which impaired goblet cell differentiation correlates with reduced expression of Muc-2 and the loss in mucincontrolled barrier function enabling luminal bacteria to invade the mucosa and trigger inflammation. ${ }^{26,45}$ Although the role of mucins in host defense has been previously reported in Muc-2-deficient mice that spontaneously develop colitis, ${ }^{27}$ little is known about the dynamic processes involved in the regeneration of the mucus layer in the context of remission in 
IBD. Employing our new model of reversible T-cell-mediated colitis, we demonstrate that in response to active intestinal inflammation, the mucin-controlled barrier function is severely compromised as demonstrated by reduced expression of Muc2. Strikingly, mucin production and the formation of the colonic mucus layer were rapidly and completely restored in response to depletion of colitogenic CD4 T cells. Importantly, restoration of the colonic mucus layer was associated with physical separation of microbes from the underlying mucosa and the regeneration of intestinal epithelial barrier integrity (Figure 4a). Although further studies are required to delineate whether a compromised mucus layer is the consequence or the cause of chronic intestinal inflammation, this model system allows studying the dynamics of mucus-controlled barrier functions in vivo under steady-state conditions, during chronic intestinal inflammation, and upon treatment-induced remission in colitis.

Evidence from human and animal studies provides compelling support that both genetic predisposition and the composition of the microbiota have key roles in initiating, maintaining, and determining the phenotype of IBD. ${ }^{39}$ Instability in the composition of gut bacterial communities (dysbiosis) has been linked to IBD and the development of colorectal cancer. ${ }^{40}$ Recent animal studies have demonstrated significant shifts in microbial clades during active colitis and following treatmentinduced remission in colitis. ${ }^{37}$ Although there is substantial evidence for changes in the composition of luminal bacteria in the context of chronic intestinal inflammation, little is known about the fine structure and dynamics of mucus-associated microbial communities and their significance in the intestine as a whole or their metabolic importance to the host. In addition to studying the restoration of the mucus layer during remission in colitis, our model system provides a powerful new tool to investigate the dynamic composition of mucus-associated bacteria in the different disease stages. It is likely that under steady-state conditions, host-adapted bacterial communities colonize the outer colonic mucus layer providing colonization resistance. Under inflammatory conditions and potential dysbiosis in mucus-associated microbial communities, luminal bacteria with mucolytic activity may gain simplified access to the mucosa and further promote disease. Analysis of mucusassociated bacterial communities using 16S rRNA gene sequencing of mucus aspirates from mice will reveal their composition in health, disease, and remission. Understanding what bacterial communities shape mucus-controlled barrier functions may help to establish new treatment protocols that promote the restoration of the mucus layer in the context of chronic inflammatory intestinal disorders.

Mucosal healing and remission in chronic intestinal inflammation involves complex temporo-spatial interactions of distinct cell types, which may be critically influenced in the microenvironment of the gut mucosa by luminal microbiota derived metabolites and constituents (e.g., short-chain fatty acids). ${ }^{41,42}$ The presented highly reproducible model of remission induction allows to further dissect these complex interactions, e.g., by specifically interfering with distinct cellular and molecular pathways using antibody-mediated depletion/ neutralization protocols to target distinct cell types and/or signaling pathways; the use of specific inhibitors, e.g., for Cox2; or by the use of conditional or inducible gene-targeted donor $\mathrm{CD} 4 \mathrm{~T}$ cells or recipient mice to directly determine their respective contribution in the induction and maintenance of mucosal healing in the intestine.

The observed rapid recovery of the mucus layer following antiCD4-mediated remission induction, together with the spatial separation of luminal bacteria from the colonic epithelium by a re-established inner mucus layer, is thus just one illustrative example on how this novel model may be used to define the critical contributions of host- and microbiota-derived factors in the induction of intestinal mucosal healing. Together, we described a reversible model of $\mathrm{T}$-cell-mediated colitis in which $\mathrm{T}$ cells are required for both development and maintenance of disease. This new model of reversible colitis will allow to further investigate key mechanisms operative in the induction of remission from colitis and/or during remitting-relapsing phases of colitis and to perform mechanistic and preclinical efficacy studies in the context of chronic intestinal remitting-relapsing disorders in a highly reproducible model system.

\section{METHODS}

Mice. Wild-type C57BL/6 Helicobacter-negative $\left(\mathrm{H}^{-}\right)$donor mice, $\mathrm{H}^{+}$ $\mathrm{Rag}^{-1-}, \mathrm{H}^{-} \mathrm{Rag}^{-1-}$, and $\mathrm{H}^{+} \mathrm{C} 57 \mathrm{BL} / 6 \mathrm{Cx} 3 \mathrm{rl}^{\mathrm{GFP} /+} \mathrm{Rag}^{-1-}$ mice were bred and housed under specific pathogen-free conditions at the central animal facility of the Medical School of the University of Bern, Bern, Switzerland. All animal experiments were performed in compliance with the Swiss law and were approved by the animal experimentation committee of the Canton of Bern.

Antibodies and flow cytometry. Anti-mouse CD11c (N418) and CD25 (PC61) antibodies were purchased from eBioscience (San Diego, CA). Anti-mouse CD45RB (16A), Ly6c (AL-21) and anti-human/ mouse Ki-67-PE (B56) antibodies were purchased from BD Pharmingen (San Diego, CA). Anti-mouse CD4 (RM4-5), CD3 (145-2C11), TCR $\alpha \beta$ (H57-597), CD45 (30-F11), Ly6G (1AB), GR-1 (RB6-8C5), CD11b (M1/70), CD64 (X54-5/7.1), MHCII (M5/114.15.2), NK11 (PK136), CD19 (6D5), CD103 (M290), Thy12 (53-2.1), and Thy11 (OX-7) were purchased from Biolegend (San Diego, CA). Biotinylated anti-mouse CD8 $\alpha$ (53-6.7) and B220 (RA3-6B2) antibodies were purified from hybridoma supernatants. Intracellular staining for Ki67 was performed using the FoxP3 staining kit from eBioscience. Dead cells were excluded using the LIVE/DEAD Fixable Dead Cell Stain Kit (blue) or DAPI (4,6-diamidino-2-phenylindole); both from Invitrogen, Carlsbad, CA in a final concentration of $0.5 \mu \mathrm{g} \mathrm{ml}^{-1}$. All samples were acquired on a LSRII or LSRII SORP (BD Biosciences, San Diego, CA) and analyzed using the Flowjo software (Tree Star, Ashland, OR).

Mouse model of reversible intestinal inflammation. Splenocytes isolated from naive wild-type Helicobacter-negative $\left(\mathrm{H}^{-}\right) \mathrm{C} 57 \mathrm{BL} / 6$ mice were enriched for $\mathrm{CD} 4{ }^{+} \mathrm{T}$ cells by magnetic-activated cell sorted depletion of $\mathrm{CD} 8 \alpha^{+}$and B220 ${ }^{+}$cells using biotinylated antibodies and streptavidin microbeads (Miltenyi Biotec, Bergisch Gladbach, Germany). CD ${ }^{+} \mathrm{CD} 45 \mathrm{RB}^{\text {hi }}$ T cells were sort purified from enriched $\mathrm{CD}^{+}{ }^{+}$T-cell suspensions on a BD FACSARIA III cell sorter (BD Biosciences, San Jose, CA). For the induction of colitis, 10-16-weekold C57BL/6 Rag ${ }^{-1-}$ mice $\left(\mathrm{H}^{+}\right.$or $\left.\mathrm{H}^{-}\right), \mathrm{H}^{+}$Thyl.1 Rag ${ }^{-1-}$, or $\mathrm{H}^{+}$ $\mathrm{Cx} 3 \mathrm{rl}^{\mathrm{GFP} /+} \mathrm{Rag}^{-1-}$ were injected intraperitoneally with $2 \times 10^{5}$ $\mathrm{CD} 4{ }^{+} \mathrm{CD} 45 \mathrm{RB}^{\mathrm{hi}} \mathrm{T}$ cells or as a control injected with $2 \times 10^{5}$ of CD4 ${ }^{+}$ $\mathrm{CD}_{45 \mathrm{RB}}{ }^{\text {lo }} \mathrm{CD} 25^{+}$Treg-enriched cells. To induce remission, mice 
with active intestinal inflammation (clinical scores 8-10) were injected intraperitoneally with a depleting antibody against CD4 (clone GK-1.5, $500 \mu \mathrm{g}$ per mouse (BioXcell, West Lebanon, NH)) or an isotype control mAb (clone LTF-2, $500 \mu$ g per mouse) with an interval of $72 \mathrm{~h}$ between the injections starting at days 9-12 or with a clinical score between 8 and 10 after CD4 T-cell transfer. For selective depletion of Thy1.2-expressing CD4 T cells transferred into Thy1.1 $\mathrm{Rag}^{-/-}$-recipient hosts, anti-Thy1.2-depleting antibodies were injected intraperitoneally (clone $30 \mathrm{H} 12,500 \mu \mathrm{g}$ per mouse (BioXcell)). For neutralization of TNF $\alpha$ or blocking of CD40-CD40L signaling, mice with active disease were injected intraperitoneally with antiTNF $\alpha$ antibodies $(500 \mu \mathrm{g}$ per mouse once daily, clone TN3-19.12, BioXcell) or anti-CD40L (500 $\mu$ g per mouse once daily, clone MR-1, BioXcell), respectively. All animals were monitored on a daily basis for weight loss and normal activity and were killed at the indicated time points or when loosing $\geqslant 20 \%$ of body weight.

Clinical and histopathological disease scoring. For clinical disease scoring, animals were monitored daily based on the following parameters: weight loss: $0-4$ : $0 \%$ weight loss $(0)$; $\leqslant 5 \%$ weight loss (1), $\leqslant 10 \%$ weight loss $(2)$; $\leqslant 15 \%$ weight loss $(3)$; and $\leqslant 20 \%$ weight loss (4). Stool consistency: 0-3: normal feces (0); loose stool (1); diarrhea for up to $24 \mathrm{~h}(2)$; and persistent diarrhea (3). Blood in the stool: $0-3$ : no blood (0); appearance of blood (1); and persistent blood in the stool (3). Behavior: 0-4: normal (0); reduced activity, piloerection (2); signs of serious pain: reduced activity, curved posture, piloerection, labored breathing (4). Maximal clinical disease score: 14. For histopathological disease scoring, colonic specimens were fixed in $4 \%$ paraformaldehyde for subsequent paraffin embedding. Deparaffinized tissue sections were stained with hematoxylin and eosin and histological scoring was performed based on the following parameters: infiltration of lamina propria of the large bowel (0-3), loss of goblet cells (0-3), crypt abscesses (0-3), epithelial erosion (0-1), hyperemia (0-2), and thickness of the colonic mucosa $(0-3)$ resulting in a maximal colitis score of 15. Investigators were blinded to treatment groups when scoring for clinical and histopathological changes.

Cell isolation. Colonic intestinal lamina propria lymphocytes and intestinal mononuclear phagocytes were isolated as described previously with minor modifications. ${ }^{43}$ Briefly, intestinal tissue pieces were stirred at two consecutive times in $\mathrm{Ca}^{2+}$ and $\mathrm{Mg}^{2+}$-free Hanks balanced salt solution (HBSS) containing $10 \mathrm{~mm}$ Hepes, $5 \%$ fetal calf serum (FCS), and $2 \mathrm{~mm}$ EDTA at $37^{\circ} \mathrm{C}$ for $20 \mathrm{~min}$. Detached cells were discarded and the remaining intestinal tissue was incubated with HBSS/HEPES buffer containing $5 \% \mathrm{FCS}$ and $100 \mathrm{U} \mathrm{ml}^{-1}$ collagenase type IV (Sigma, St Louis, $\mathrm{MO}$ ) and $50 \mathrm{U} \mathrm{ml}^{-1}$ DNase (type I, grade II; Roche Diagnostics, Indianapolis, IN) at $37^{\circ} \mathrm{C}$ for $30 \mathrm{~min}$. Isolated cells from the lamina propria were then passed through a $40-\mu \mathrm{m}$ pore size for subsequent counting and fluorescence-activated cell sorting analysis. Cells from the lymph nodes and spleen were isolated by grinding the organs between the frosted ends of two glass slides followed by filtering through $40-\mu \mathrm{m}$ cell strainers. Cells were gated as following as singlet, live cells: dendritic cells: $\quad \mathrm{CD}_{4} 5^{+} \mathrm{CD} 3{ }^{-} \mathrm{NK} 1.1^{-} \mathrm{CD}{ }^{-}{ }^{-} \mathrm{Ly}_{6 \mathrm{G}}{ }^{-} \mathrm{MHCII}^{+} \mathrm{CD} 11 \mathrm{c}^{+}$; macrophages: $\quad \mathrm{CD}_{4} 5^{+} \mathrm{CD} 3{ }^{-} \mathrm{NK} 1.1^{-} \mathrm{CD} 19^{-} \mathrm{Ly}_{6 \mathrm{G}}{ }^{-} \mathrm{MHCII}^{+}$ $\mathrm{CD}^{+}{ }^{+}$; neutrophils: $\mathrm{CD} 45^{+} \mathrm{CD} 3{ }^{-} \mathrm{NK} 1.1^{-} \mathrm{CD}^{-} 9^{-} \mathrm{Ly}_{6 \mathrm{G}}{ }^{-}$ $\mathrm{CD}_{11}{ }^{+} \mathrm{GR}^{+}{ }^{+}$; monocytes: $\mathrm{CD} 45^{+} \mathrm{CD} 3{ }^{-} \mathrm{NK} 1.1^{-} \mathrm{CD}^{-} 9^{-} \mathrm{Ly}_{6 \mathrm{G}}{ }^{-}$

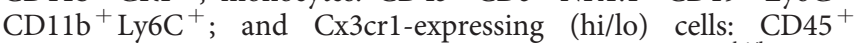
$\mathrm{CD}^{-}{ }^{-} \mathrm{NK} 1.1^{-} \mathrm{CD}^{-} 9^{-} \mathrm{Ly}_{6 \mathrm{G}}{ }^{-} \mathrm{CD} 11 b^{+} \mathrm{GR}^{-}{ }^{-} \mathrm{Ly}_{6 \mathrm{c}^{+}} \mathrm{GFP}^{\text {hi/lo }}$.

RNA isolation, cDNA synthesis, and quantitative real-time RT PCR. RNA was isolated from the indicated tissues using TRIzol according to the manufacturer's instructions (Molecular Research Centre, Cincinnati, OH). Genomic DNA was digested with DNase I (Ambion, Austin, TX), and cDNA was generated using the High Capacity Reverse Transcription Kit (Applied Biosystems, Carlsbad, CA). For Custom RT Profiler PCR arrays, samples were run with RT SYBR green ROX Fast on an Applied Biosystems 7900HT Fast Real-Time PCR system. Expression of genes was normalized to Gapdh and $\beta 2$-microglobulin. Real-time PCR was performed using the Sequence Detection System software version 1.2.2 (Applied Biosystems).

Immunofluorescence and 16S rRNA in situ hybridization. Colonic tissues containing luminal contents were fixed in Methanol-Carnoy's fixative (dry methanol, Chloroform, glacial acetic acid, ratio 6:3:1). Fixed tissues were consecutively washed in methanol, ethanol, and xylene prior to embedding in paraffin. Paraffin-embedded tissue samples were cut in $6-\mu \mathrm{m}$-thin tissue sections, deparaffinized in xylene, and hydrated for immunostaining and fluorescence in situ hybridization. Paraffin-embedded MetOH-Carnoy-fixed tissue sections were stained with Alcian blue2.5/periodic acid-Schiff. ${ }^{22}$ Fluorescence in situ hybridization was performed using a general bacterial $16 \mathrm{~S}$ rRNA probe (EUB338). ${ }^{46}$ Immunostaining for Muc-2 was performed using an antiMuc-2 polyclonal rabbit IgG antibody (Santa Cruz Biotechnologies, Dallas, TX, Clone H-300) and an Alexa488-conjugated anti-rabbit IgG antibody (Invitrogen). DAPI was used to counterstain DNA for immunostaining and fluorescence in situ hybridization, and sections were analyzed using confocal microscope (Olympus FV1000, Olympus Europe, Hamburg, Germany).

Cytokine detection. For detection of protein levels of pro-inflammatory mediators in the serum and colon homogenates Bead-based multiplex assays (Mouse cytokine/chemokine Array 31plex, Eve Technologies, Calgary, Alberta, Canada) were performed or enzymelinked immunosorbent assay to detect $\mathrm{TNF} \alpha$ in the serum of mice.

Endoscopy. Remission in mice with colitis was monitored upon depletion of colitogenic CD4 T cells at the indicated time points with a high-resolution video endoscopic system (Karl Storz IMAGE1 System, Tuttlingen, Germany).

Statistics. All data were analyzed using Graphpad Prism 6 (La Jolla, CA). Results are shown as mean \pm s.d. Statistical significance was determined using one-way analysis of vaiance with Tukey's multiple or Dunn's multiple comparison test. Results were considered significant at $P \leqslant 0.05$. ${ }^{\star} P<0.05 ;{ }^{* *} P<0.01 ;{ }^{* * *} P<0.005$; and ${ }^{* * * *} P<0.001$.

SUPPLEMENTARY MATERIAL is linked to the online version of the paper at http://www.nature.com/mi

\section{ACKNOWLEDGMENTS}

We thank the members of the Mueller laboratory for discussions and critical reading of the manuscript. We also thank the Center for Flow Cytometry and Cell Sorting Resource of the Department of Clinical Research, University of Bern for technical advice and support. This work was supported by the Swiss National Science Foundation Sinergia grant to A.J.M., C.M., W.D.H., and D.F. and SNSF grant no. 31-138392 to C.M.

\section{DISCLOSURE}

The authors declared no conflict of interest.

(c) 2016 Society for Mucosal Immunology

\section{REFERENCES}

1. Khanna, P.V., Shih, D.Q., Haritunians, T., McGovern, D.P. \& Targan, S. Use of animal models in elucidating disease pathogenesis in IBD. Semin. Immunopathol. 36, 541-551 (2014).

2. D'Haens, G.R., Sartor, R.B., Silverberg, M.S., Petersson, J. \& Rutgeerts, P. Future directions in inflammatory bowel disease management. J. Crohns Colitis 8, 726-734 (2014).

3. Merga, Y., Campbell, B.J. \& Rhodes, J.M. Mucosal barrier, bacteria and inflammatory bowel disease: possibilities for therapy. Dig. Dis. 32, 475-483 (2014).

4. Johansson, M.E.V. et al. Bacteria penetrate the normally impenetrable inner colon mucus layer in both murine colitis models and patients with ulcerative colitis. Gut 63, 281-291 (2013). 
5. Johansson, M.E.V. et al. Bacteria penetrate the inner mucus layer before inflammation in the dextran sulfate colitis model. PLoS One 5, e12238 (2010).

6. Pickert, G. et al. STAT3 links IL-22 signaling in intestinal epithelial cells to mucosal wound healing. J. Exp. Med. 206, 1465-1472 (2009).

7. Neufert, C. et al. Activation of epithelial STAT3 regulates intestinal homeostasis. Cell Cycle 9, 652-655 (2010).

8. Tschurtschenthaler, M. et al. Type I interferon signalling in the intestinal epithelium affects Paneth cells, microbial ecology and epithelial regeneration. Gut, 2013-305863 (2014).

9. Seno, H. et al. Efficient colonic mucosal wound repair requires Trem2 signaling. Proc. Natl. Acad. Sci. USA 106, 256-261 (2009).

10. Hsu, D. et al. Toll-like receptor 4 differentially regulates epidermal growth factor-related growth factors in response to intestinal mucosal injury. Lab. Invest. 90, 1295-1305 (2010).

11. Peterson, L.W. \& Artis, D. Intestinal epithelial cells: regulators of barrier function and immune homeostasis. Nat. Rev. Immunol. 14, 141-153 (2014).

12. Peterson, L.W. et al. Intestinal epithelial cells: regulators of barrier function and immune homeostasis. Nat. Rev. Immunol. 14, 141-153 (2014).

13. Artis, D. Epithelial-cell recognition of commensal bacteria and maintenance of immune homeostasis in the gut. Nat. Rev. Immunol. 8, 411-420 (2008).

14. Sonnenberg, G.F., Monticelli, L.A., Elloso, M.M., Fouser, L.A. \& Artis, D. $\mathrm{CD} 4(+)$ lymphoid tissue-inducer cells promote innate immunity in the gut. Immunity 34, 122-134 (2011).

15. Endt, K. et al. The microbiota mediates pathogen clearance from the gut lumen after non-typhoidal salmonella diarrhea. PLoS Pathog. 6, e1001097 (2010).

16. Chassaing, B., Aitken, J.D., Malleshappa, M. \& Vijay-Kumar, M. Dextran sulfate sodium (DSS)-induced colitis in mice. Curr Protoc Immunol 104, Unit15.25 (2014)

17. Mottet, C., Uhlig, H.H. \& Powrie, F. Cutting edge: cure of colitis by CD4 + CD25 + regulatory T cells. J. Immunol. 170, 3939-3943 (2003).

18. Uhlig, H.H. et al. Characterization of Foxp3 + CD4 + CD25 + and IL-10secreting CD4 + CD25 + T cells during cure of colitis. J. Immunol. 177, 5852-5860 (2006)

19. Hart, A.L. et al. Homing of immune cells: role in homeostasis and intestinal inflammation. Inflamm. Bowel Dis. 16, 1969-1977 (2010).

20. Lawrance, I.C. Modifying T-cell trafficking to the intestinal as a potential management for inflammatory bowel disease. Expert Opin. Investig. Drugs 21, 975-984 (2012).

21. Podolsky, D.K. et al. Attenuation of colitis in the cotton-top tamarin by antialpha 4 integrin monoclonal antibody. J. Clin. Invest. 92, 372-380 (1993).

22. Wlodarska, M. et al. NLRP6 inflammasome orchestrates the colonic hostmicrobial interface by regulating goblet cell mucus secretion. Cell 156, 1045-1059 (2014).

23. Songhet, P. et al. Stromal IFN- $\gamma$ R-signaling modulates goblet cell function during Salmonella Typhimurium infection. PLoS One 6, e22459 (2011).

24. Farin, H.F. et al. Paneth cell extrusion and release of antimicrobial products is directly controlled by immune cell-derived IFN. J. Exp. Med. 211, 13931405 (2014).

25. Sugimoto, K. et al. IL-22 ameliorates intestinal inflammation in a mouse model of ulcerative colitis. J. Clin. Invest. 118, 534-544 (2008).

26. Bergstrom, K.S.B. et al. Muc2 protects against lethal infectious colitis by disassociating pathogenic and commensal bacteria from the colonic mucosa. PLoS Pathog. 6, e1000902 (2010).

27. Van der Sluis, M. et al. Muc2-deficient mice spontaneously develop colitis, indicating that MUC2 is critical for colonic protection. Gastroenterology 131, 117-129 (2006).
28. McGuckin, M.A., Eri, R., Simms, L.A., Florin, T.H.J. \& Radford-Smith, G. Intestinal barrier dysfunction in inflammatory bowel diseases. Inflamm. Bowel Dis. 15, 100-113 (2009).

29. Corazza, N., Eichenberger, S., Eugster, H.P. \& Mueller, C. Nonlymphocytederived tumor necrosis factor is required for induction of colitis in recombination activating gene (RAG)2(-/-) mice upon transfer of CD4(+) CD45RB(hi) T cells. J. Exp. Med. 190, 1479-1492 (1999).

30. Atreya, R. et al. Blockade of interleukin 6 trans signaling suppresses T-cell resistance against apoptosis in chronic intestinal inflammation: evidence in Crohn disease and experimental colitis in vivo. Nat Med 6, 583-588 (2000).

31. Mahmud, N., McDonald, G.S., Kelleher, D. \& Weir, D.G. Microalbuminuria correlates with intestinal histopathological grading in patients with inflammatory bowel disease. Gut 38, 99-103 (1996).

32. Sturm, A. \& Dignass, A.U. Epithelial restitution and wound healing in inflammatory bowel disease. World J. Gastroenterol. 14, 348-353 (2008).

33. Schnitzler, F. et al. Mucosal healing predicts long-term outcome of maintenance therapy with infliximab in Crohn's disease. Inflamm. Bowel Dis. 15, 1295-1301 (2009).

34. Colombel, J.-F. et al. Early mucosal healing with infliximab is associated with improved long-term clinical outcomes in ulcerative colitis. Gastroenterology 141, 1194-1201 (2011).

35. Wirtz, S., Neufert, C., Weigmann, B. \& Neurath, M.F. Chemically induced mouse models of intestinal inflammation. Nat. Protoc. 2, 541-546 (2007).

36. Neurath, M.F. et al. Predominant pathogenic role of tumor necrosis factor in experimental colitis in mice. Eur. J. Immunol. 27, 1743-1750 (1997).

37. Rooks, M.G. et al. Gut microbiome composition and function in experimental colitis during active disease and treatment-induced remission. ISME J. 8, 1403-1417 (2014).

38. Fox, J.G., Ge, Z., Whary, M.T., Erdman, S.E. \& Horwitz, B.H. Helicobacter hepaticus infection in mice: models for understanding lower bowel inflammation and cancer. Mucosal Immunol. 4, 22-30 (2011).

39. Kullberg, M.C., Jankovic, D., Feng, C.G., Hue, S., McKenzie, B.S. \& Cua, D.J. et al. IL-23 plays a key role in Helicobacter hepaticus-induced T cell-dependent colitis. J. Exp. Med. 203, 2485-2494 (2006).

40. Sun, L. et al. Host genetic susceptibility, dysbiosis, and viral triggers in inflammatory bowel disease. Curr. Opin. Gastroenterol. 27, 321-327 (2011).

41. Cario, E. Commensal-innate immune miscommunication in IBD pathogenesis. Dig. Dis. 30, 334-340 (2012).

42. De Jong, Y.P., Comiskey, M., Kalled, S.L., Mizoguchi, E., Flavell, R.A. \& Bhan, A.K. et al. Chronic murine colitis is dependent on the CD154/CD40 pathway and can be attenuated by anti-CD154 administration. Gastroenterology 119, 715-723 (2000).

43. Arpaia, N. et al. Metabolites produced by commensal bacteria promote peripheral regulatory T-cell generation. Nature 504, 451-455 (2013).

44. Smith, P.M. et al. The microbial metabolites, short-chain fatty acids, regulate colonic Treg cell homeostasis. Science 341, 569-573 (2013).

45. Medina-Contreras, O. et al. CX3CR1 regulates intestinal macrophage homeostasis, bacterial translocation, and colitogenic Th17 responses in mice. J. Clin. Invest. 121, 4787-4795 (2011).

46. Van den Brande, J.M.H. et al. Infliximab but not etanercept induces apoptosis in lamina propria T-lymphocytes from patients with Crohn's disease. Gastroenterology 124, 1774-1785 (2003).

47. Hasnain, S.Z. et al. Mucin gene deficiency in mice impairs host resistance to an enteric parasitic infection. Gastroenterology 138, 1763-1771 (2010).

48. Lücker, S. et al. Improved $16 \mathrm{~S}$ rRNA-targeted probe set for analysis of sulfate-reducing bacteria by fluorescence in situ hybridization. J. Microbiol. Methods 69, 523-528 (2007). 